Egypt. Acad. J. biolog. Sci., 1 (2) 13 - 25 (2008)

E. mail.: egyptianacademicr@yahoo.com

ISSN: $1687-8809$

Received: $15 / 7 / 2008$

\title{
Effect of flufenoxuron on the antennal sensilla of Spodoptera littoralis (Lepidoptera: Noctuidae).
}

\author{
Nasra M.H.Zohry \\ Department of Zoology, Faculty of Science, Sohag, South Valley University, Egypt.
}

\section{ABSTRACT}

In the present study, the effect of flufenoxuron on the sensory organ in the antenna of Spodoptera littoralis was showed after feeding of the $3^{\text {rd }}$ larval instars for $24 \mathrm{hrs}$. on treated castor been leaves with $\mathrm{Lc}_{50}$. Each adult antenna, male and female of untreated and treated group is divided into about 77-82 segment like annuli; and each segment is divided into a sensory region containing the olfactory sensilla and a largely non-sensory region containing scales and a very small number of sensory structures.

Six types of sensilla were found on the antenna of adult S. littoralis: by scanning electron microscopy. These sensilla were trichoidae, chaetica, coeloconica, taste rod, sensilla auricillica and squamiforms.

Two types of sexually dimorphic trichoidae were found; Type I is in the peripheral of the sensory field of the flagellar segments and present only on male antennae. This suggests that the sensillum may contain the receptor sites for the female sex pheromone. Type II is located within the ventromedial sensillar field of male and female where they are arranged without apparent pattern.

Six mechanoreceptive sensilla chaetica on each segment of male and female were particularly abundant on the apical antennal segment.

Each flagellar segment bears several sensilla coeloconica on the ventral surface of the antennae. Each sensillum consists of a depression surrounded by 15 to 17 teeth and one peg.

There was a single sensillum taste rod on each segment. There is one of these sensilla at each segment in both male and female. On the terminal segment there were two sensilla joined.

Sensilla auricillica were found on both male and female. These sensilla usually had a typical rabbit ear shape.

The squamiform sensilla are found on both male and female on the dorsal part of the antenna among the scales.

The study revealed that $\mathrm{LC}_{50}$ of flufenoxuron caused the formation of abnormal antennae and effect the length and distribution of the sensilla.

Key words: antennal sensilla, Lepidoptera, Noctuidae, insect growth regulators.

\section{INTRODUCTION}

Insect antennae are mobile, segmented, paired head- appendages and are found in nearly all insect groups (Gullan and Cranton, 1994; Schneider, 1964). Numerous sensory organs, or sensilla occur on antennae in the form of hairs, pegs, pits or cones. Functions of antennal sensilla include chemoreceptivity (gustatory and olfactory), mechanoreceptivity, thermoreceptivity, hygroreceptivity and $\mathrm{CO}_{2}$ receptivity (Keil, 1999). 
The major economic crop (the cotton plant) in Egypt was greatly attacked by many pests from seedling stage till harvest causing various degrees and types of damage. The cotton leaf worm, S. littoralis (Boisd) in particular causes serious damage to cotton plant and others of more than 112 plant species.

We used the technique of scanning electron microscopy to identify the antennal sensilla of $S$. littoralis and the effect of insect growth regulators on the antennal sensilla especially sensilla specific for the sex phermone. This basic information will be important in future studies aimed to the sex pheromone of this moth species, an understanding of how these changes could be considerable importance in knowing how better to control them.

\section{MATERIALS AND METHODS}

Spodoptera littoralis (Boisd) larvae obtained from the laboratory culture of plant protection, Research Institute, Agricultural, Research Center, Cairo, Egypt. The insects were obtained from a colony reared in the laboratory under constant laboratory conditions of $27 \pm 2 \mathrm{C}$ and $70 \pm 5 \% \mathrm{R}$. H. The effect of flufenoxuron on the sensory organ in the antenna of $S$. littoralis was recorded after feeding the $3^{\text {rd }}$ larval instars for $24 \mathrm{hrs}$. on treated castor bean leaves with $\operatorname{LC}_{50}(0.335 \mathrm{ppm})$, then transferring the larvae to untreated ones.

The fine structure and distribution of various types of antennal sensilla in one day old female and male resulting from larval instar treated with $0.335 \mathrm{ppm}$ flufenoxuron, was compared with those of untreated individuals by using scanning electron microscopy (SEM).

The antennae of 15 males and 15 females of both untreated and treated groups were separately placed in a solution of $1 \%$ glutaldehyde. After completion of fixation, wash the specimen in cacodylate buffer with $\mathrm{pH}=6.8$ for three times each for $20 \mathrm{~min}$. They were dehydrated in 30\%, 50\%, 70\%, 90\% and 100\% (three times) ethanol and each for 15 min. After wards, they were dried at critical point and finally coated with gold using sputter coating for examination by using scanning electron microscopy (SEM), JEOL, JSM 5300.

\section{RESULTS}

\section{External morphology and distribution of sensilla}

The antennae of $S$. littoralis is filiform and segmented. Each antenna consists of two basal segments: The scape and the pedicel. The number of segments in untreated male and female is $77.67 \pm 3.480$ and $79.67 \pm 2.186$, respectively (Table1). The flagellar segments increase in length and diminish in diameter from the base to the apex of the antennae. A typical antennal segment is cylindrical and divided into two main areas: The dorsal surface has two rows of scales; the second row overlaps the first row of the following segment (Fig.1A). The only obvious type of dorsal sensillum is the squamiform type. The ventral surface possesses most of the sensilla.

Table 1: The total length and number of segments in the antenna of male and female of S. littoralis.

\begin{tabular}{|c|c|r|r|r|}
\hline Sex & \multicolumn{1}{|c|}{$\begin{array}{c}\text { Total length of the } \\
\text { antenna }(\mathrm{mm})\end{array}$} & \multicolumn{1}{c|}{$\begin{array}{c}\text { Number of } \\
\text { segments }\end{array}$} & \multicolumn{1}{c|}{$\begin{array}{c}\text { Length of } \\
\text { segments }(\mu \mathrm{m})\end{array}$} & \multicolumn{1}{c|}{$\begin{array}{c}\text { Width of segments } \\
(\mu \mathrm{m})\end{array}$} \\
\hline Male (untreated) & $8.75 \pm 0.273$ & $77.670 \pm 3.480$ & $98.542 \pm 2.760$ & $113.517 \pm 16.428$ \\
\hline Female (untreared) & $9.29 \pm 0.019$ & $79.670 \pm 2.186$ & $108.850 \pm 3.778$ & $108.900 \pm 7.342$ \\
\hline Male(treatment) & $9.13 \pm 0.074$ & $76.670 \pm 5.548$ & $102.267 \pm 7.799$ & $91.400 \pm 10.940$ \\
\hline Female (treatment) & $9.51 \pm 0.095$ & $82.333 \pm 0.667$ & $112.183 \pm 2.982$ & $111.308 \pm 6.205$ \\
\hline
\end{tabular}




\section{Effect of flufenoxuron on the antennal sensilla of Spodoptera littoralis}

There are six types of sensilla on the flagellum: trichoidea, chaetica, coeloconica, taste rod, sensilla auricillica and squamiforms sensilla were recorded in both untreated and treated group.

Males and females have the same types of sensilla on the ventral surface of flagellar segments, except for the lateral chemreceptive trichoid sensilla (typeI), which are present only on male.

The chemoreceptive trichoid sensilla are the most numerous type. They can be divided into two types according to their external structure and location.

Type I, present only on the antenna of male are long ranged between 104$116 \mu \mathrm{m}$ in length, slightly curved and perpendicular to the antennae (Fig.1B). The total number of these sensilla was estimated to be 1810-2400 sensilla.

Type II sensilla are shorter than type I sharply taper trichodea and are present

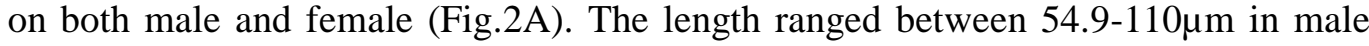
and $36.1-60 \mu \mathrm{m}$ in female. They are not arranged in rows. Some of these sensilla are more curved than others. Type II are localized on the ventral surface of each segment and the total number of these sensilla was estimated to be 1356-2270 in male and 1628-2040 in female. The most common sensillum type was trichoid sensilla ( 80\% of total sensilla).

Each segment on the male and female antennae bear six mechanoreceptive sensilla chaetica (Fig.2B) except the apical segment which has more than six (Fig.3A). Each sensillum is straight, wide at the basal part and slightly curved at the distal part, rounded and without a pore. These can be divided into two groups according to their length and location. Long chaetica sensilla, found on the superior dorsal surface and lateroventrally (Fig.3B). These sensilla are ranged between $80-110 \mu \mathrm{m}$ in length in male and 50- $75 \mu \mathrm{m}$ in length in female. The number of these sensilla was the same in both male and female about 360-420.

Contrasting with this, are the short chaetica sensilla, localized on the medioventral surface (Fig.4A). These sensilla are ranged between $37.2-68.4 \mu \mathrm{m}$ in length in male and 31.3-50 $\mu \mathrm{m}$ in female. The number of these sensilla was 144-168 in male and female.

Chaetica are grooved circumferentially (Fig.4B). They are generally hair or bristle like and are set into a basal socket (Fig.5A).

The coeloconica sensilla are present on the antennae of both male and female. Usually they are present on the ventral surface (Fig.5B). They are situated mainly from the seventh segment to the terminal portion of the segment. Their overall diameter lies between $9.29 \mu \mathrm{m}$ and $13.3 \mu \mathrm{m}$ in both male and female. The number of these sensilla lies between 4 to 6 in each segment. Each sensillum consists of a depression surrounded by 15 to 17 circular spines and central peg is fluted and appear as a cone.

A single taste rod (Fig.6A\&Fig.6B) has been found on each segment of all the examined antennae examined. They are invariably situated at the leading edge of each segment and in the center of the sensillum. The length ranged between $20.6-28.1 \mu \mathrm{m}$ in male and $12.4-14.1 \mu \mathrm{m}$ in female. Taste rods having three cavity peg complexes at their tip (Fig.7A). Often there is one of these sensilla at each segment in both male and female. On the terminal segment there are two joined taste rods (Fig.7B).

Sensilla auricillica were found on the lateral part of the antennal segment, close to the bearing dorsal surface (Fig.8A). These sensilla usually had a typical rabbit ear shape and found on both male and female. 
Squamiformia structures were found on the dorsal part of the antenna among the scales. The base is inserted into a socket and is pointed distally (Fig.8B).The length ranged between $50-67.4 \mu \mathrm{m}$ in male and $40.4-48.8 \mu \mathrm{m}$ in female.

\section{Effect of flufenoxuron on the antennal adult of $S$. littoralis}

Scanning electron microscopy of adult antenna from treated $3^{\text {rd }}$ larval instar with $\mathrm{LC}_{50}$ of flufenoxuron revealed that, the antennae of treated group are loss their normal shape and the number of segments in male is $76.670 \pm 5.548$ and $82.333 \pm$ 0.667 in female (Table 1).

Flufenoxuron caused several abnormalities especially in the antenna of adult male (Figs.9,10\&11). In treated group the length and the number of the trichoid sensilla are affected. The length of type I are ranged between $60-107 \mu \mathrm{m}$ and the total number of these sensilla was decrease and estimated to be 535-1410 sensilla. The length of type II sensilla are ranged between $27.1-90.5 \mu \mathrm{m}$ in male and $36.1-38.9 \mu \mathrm{m}$ in female. The total number of type II in male are ranged between 1266-1825 in male and 2052-2035 in female.

In treated group long and short chaetica sensilla length are ranged between $75.5-100 \mu \mathrm{m}$ and $31.4-60 \mu \mathrm{m}$ respectively, in male and $50-108 \mu \mathrm{m}$ and $12.4-58 \mu \mathrm{m}$ respectively in female.

\section{DISCUSSION}

The general structure of the antenna of $S$. littoralis is similar to that in other noctuids: Copitarsia consueta (Comez et al., 1999), Trichoplusia ni (Hübner), Helicoverpa zea (Boddie), Spodoptera ornithogalli (Gueneé), Spodoptera exigua (Hübner) (Jefferson et al., 1970), and Pseudaletia unipuncta (Haworth) (Lavoie and McNeil, 1987). Typically scales occur along with sensilla on the surface of the noctuid antenna. Van der pers et al. (1980), who do not believe that scales protect the sensilla from mechanical damage, but rather suggest that their position contributes to the insect's ability to detect the direction of the stimulus. Wall (1978) argued that scales may be a mechanism to trap and concentrate odorous molecules.

There is sexual dimorphism in S. littoralis antennae. The antenna of the male has a large number of long trichoid sensilla which are absent in the female. The presence of these sensilla has also been reported in other noctuids: Helicoverpa zea (Callahan, 1969), T.ni ,H.zea, S. ornithogalli and S. exigua (Jefferson et al. 1970). It has been demonstrated in several moths that the long trichoid sensilla on the antenna of the male are receptors for the sex pheromone of the female (Boekh et al., 1965, Schneider; Steinbrecht, 1968, Van der pers and Den Otter 1978, Kaissling 1979, Zacharuk, 1985).

Franco et al. (2007) reported that in male antennae of Manduca sexta each sensory region is further divided into a peripheral domain containing the sexphermone specific sensilla trichoidae surrounding a central domain containing several classes of intermixed sensilla responsive to plant volatile including short trichoidae sensilla, basiconica and coeloconica but in female antennae lake of the long trichoidae that specific for the sex pheromone.

Transmission electron microscope studies (Lewis 1971, Schneider and Steinbrect 1968) have shown that trichoidea are covered with pores which, however are too small in most insects to be resolved by the scanning electron microscope.

Chaetica sensilla of $S$. littoralis are similar in structure to those reported for other noctuids by Callahan (1969), Jefferson et al. (1970) and Liu and Liu (1984). They were suggested to be contact chemoreceptors in T. ni, S. ornithogalli ( Jefferson 


\section{Effect of flufenoxuron on the antennal sensilla of Spodoptera littoralis}

et al. 1970), but to have a mechanoreceptive function in a mosquito (Davis and Sokolove, 1975).

Coeloconica sensilla, mostly present on each segment of males and females of $S$. littoralis from the seventh to the terminal part have also been found in other noctuids, $P$. unipuncta (Lavoie and McNeil, 1987), and a pyralids (Cornford $\boldsymbol{e t}$ al., 1973). Three to four sensilla occur per segment of males and females in Ostrinia nubilalis and Pyralids ( Cornford et al. 1973 and Faucheux, 1991). There was no size variation in these sensilla on the antennae of either sex of $S$. littoralis. Such sensilla have been considered to be temperature receptors in a mosquito (Davis and Sokolove, 1975) and a cockroach. In the latter insect, they are also sensitive to humidity (Altner et al., 1977). However their ultrastructure suggests they are olfactory receptors, Possibly sensitive to volatile odors of plants (Van der pers, 1981).

Flower and Helson (1971\&1974) suggested that all the main types of sensillum were present in some form on the noctuid moth examined are capable of perceiving broadly similar stimuli from their surroundings. It is surprising to find that some sensilla (taste rod and chaetica) vary so little; a possible explanation of this invariance can be found in their probable functions.

Chaetica appear to be used for infrared detection (Callahan 1969), and as the same general wave lengths are probably being perceived. Similarly, taste pegs have been suggested as having a gustatory function (Callahan 1969), and it may be that the food requirements.

In the present study, flufenoxuron with sublethal dose caused abnormalities in the shape of the antenna and change in the length and the number of these sensilla especially trichoid and chaetica sensilla. The length and the number of long trichoid in male are affected which specific for the female sex pheromone. These abnormalities may be attributed to the effect of insect growth regulator on the release of ecdysteroids indirectly, by interfering with the neuroendocrine sites responsible for the release of this hormone.

Timothy, (2005) reported that an increased number of sensilla, through lengthening, branching or thickening of antennal segments would also increased sensitivity, while, Franco et al. (2007) stated that each sensillum contains one to several sensory neurons and at least three support cells; these cells arise from mitotic activities from one or a small group of defined precursor cells. These mitotic activities of epidermal cells is enhanced by ecdysteroids. Also, Franco et al. (2007) reprted that the adult antennae deriving from imaginal primordial that initiate growth during the larval instar and continue to develop throughout the metamorphic pupal stage. Generally, it should be pointed out that the general abnormalities in adult antenna as a result of treatment the third larval instar with $\mathrm{LC}_{50}$ of flufenoxuron and the change in number and length in the sensilla especially trichoid and chaetica sensilla may be one of the reasons that IGRs caused blocks the maturation of imaginal discs which are the primordial of adult integument structure in the endopterygote insects.

REFERENCES

Altner, H.; Sas, H. and Altner, I. (1977). Relationship between structure and function of antennal chemo-hygro, and thermo-receptive sensilla in Periplaneta americana. Cell Tissue Res., 176: 389-405.

Boekh, J.; Kaissling, K. E. and Schineider, D. (1965). Insect olfactory receptors. Cold Spring Harbor Symp. Quant. Biol., 30. 
Callahan, P. S. (1969). The exoskeleton of the corn earworm moth, Heliothis zea (Lepidoptera; Noctuidae) with special reference to the sensilla as polytubular dielectric arrays. Univ. Georgia Coll. Agric. Exp. Stn. Res. Bull., 54:1-105.

Comez, V. R. C.; Jorge, V. C.; Juan, C.T.; Mario, C. L. and Rodolfo, O. O. (1999). Morphology and distribution of the sense organs on the antennae of Copitarsia consueta (Lepidoptera: Noctuidae). Florida Entomologist: 82 (4): 546-555.

Cornford, M. E.; Rowley, W. A. and Klun, J. A. (1973). Scanning electron microscopy of antennal sensilla of the European corn borer, Ostrinia nubilalis. Ann. Entomol. Soc. America, 66: 1079-1088.

Davis, E. E. and Sokolove, P. G. (1975). Temperature responses of antennal receptors of the mosquito Aedes aegypti. J. Comp. Physiol., 6:223-236.

Faucheux, M. J. (1991): Morphology and distribution of sensilla on the cephalic appendages, tarsi and ovipositor of the European sunflower moth, Homoeosoma nebulella Den. and Schiff. (Lepidoptera: Pyralidae). Int. J. Insect Morphol. Embryol., 20: 291-307.

Flower, N. E. and Helson, G. A. H. (1971). The structure of sensors on the antennae and proboscis of Heliothis armigera conferta Hubn.N.Z. J. sci., 14 (4):810-15.

Flower, N. E. and Helson, G. A. H. (1974). Variation in antennal sensilla of some noctuid moths: a scanning electron microscope study. N.Z. J. Zool., 1(1): 59-66.

Franco, M. D.; Bohbot, J.; Fernandez, K.; Hanna, J.; Poppy, J. and Vogt, R. (2007). Sensory cell proliferation within the olfactory epithelium of developing adult Manduca sexta (Lepidoptera). PLoS ONE 2(2): e215.

Gullan, P. J. and Cranston, P. S. (1994). The insects an outline of entomology. Chapman \& Hall, London.

Jefferson, R. N.; Rubin, R. E.; Mcfarland, S. U. and Shorey, H. H. (1970). Sex phermones of noctuid moths, XXII. The external morphology of the antennae of Trichoplusia ni, Heliothis Zea, Prodenia ornithogalli and Spodoptera exigua. Ann. Entomol. Soc. Amer., 63: 1227-1238.

Kaissling, K. E. (1979). Recognition of phermones by moths, especially in saturniids and Bombyx mori. P. 43-56 in F. J. De Ritter (Ed.) Chemical Ecology: Odour Communication in Animals. Elsevier, Amsterdam.

Keil, T. A. (1999). Morphology and development of the peripheral olfactory organs. In Insect olfaction, pp. 5-47 (ed. B. S. Hansson). Springer, New York.

Lavoie, D. J. and McNeil, J. N. (1987). Sensilla of the antennal flagellum in Pseudaletia unipuncta (Haw.) (Lepidoptera: Noctuidae). Int.J.Insect Morphol. Embryol., 16: 153-167.

Lewis, C. T. (1971). Superficial sense organs of the antennae of the fly, Stomoxys calcitrans. J. Insect Physiol., 17:449-61.

Liu, H. J. and Liu, T. P. (1984). Sensilla on the antennal flagellum of the bertha army worm, Mamestra configurata Walker (Lepidoptera: Noctuidae). Ascanning electron microscope study. Ann. Entomol. Soc. America, 77: 235-245.

Schneider, D. (1964). Insect Antennae. Annual Review of Entomol., 9: 103-122.

Schneider, D. and Steinbrecht, R. A. (1968). Check list of insect olfactory sensilla. Symp. Zool. Soc. London, 23: 279-297.

Timothy, C. (2005). External morphology of antennal sensilla in relation to the host searching behaviour of Liporrhopalum tentacularis Grandi (Hymenoptera: Agaonidae). BLGY 3040 Project Report. 
Van Der Pers, J. N. C. (1981). Comparison of electroantennogram response spectra to plant volatiles in seven species of Yponomeuta and in the Tortricid adoxophyes orana. Entomol. Exp. Appl., 30: 181-192.

Van Der Pers, J. N. C.; Cuperus, P. L. and Den otter, C. J. (1980). Distribution of sense organs on male antennae of small ermine moths, Yponomeuta sp. (Lepidoptera: Yponomeutidae). Int. J. Insect Morphol. Empryol., 9: 15-23.

Van Der Pers, J. N. C. and Den Otter, C. J. (1987). Single cell responses from olfactory receptors of small ermine moths (Lepidoptera:Yponomeutidae) to sex attractants. J. Insect Physiol, 24: 337-343.

Wall, C. (1978). Morphology and histology of the antenna of Cydia nigricana (F.) (Lepidoptera: Tortricidae). Int. J. Insect Morphol. Embryol., 7: 237-250.

Zacharuk, R. Y. (1985). Antennae and sensilla.P.1-69 in Comprhensive Insect Physiol. Biochem. and Pharmacol., Vol.6. Pergamon Press, Oxford. 


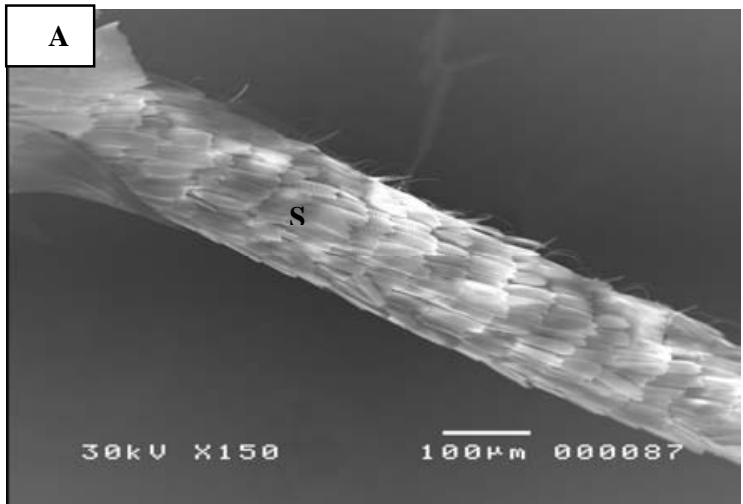

(A): General view of antennal segment of female showing scales (S).

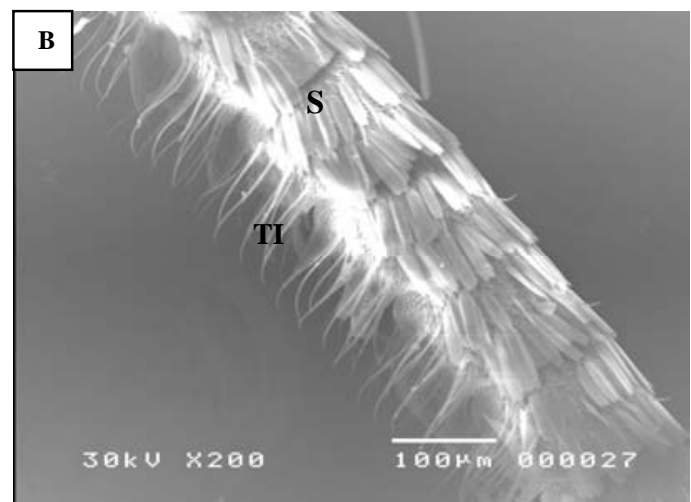

(B): Type I (TI) of trichoid sensilla, present only on male.

Fig. (1): Scanning electron microscopy of antennal sensilla of untreated S. littoralis

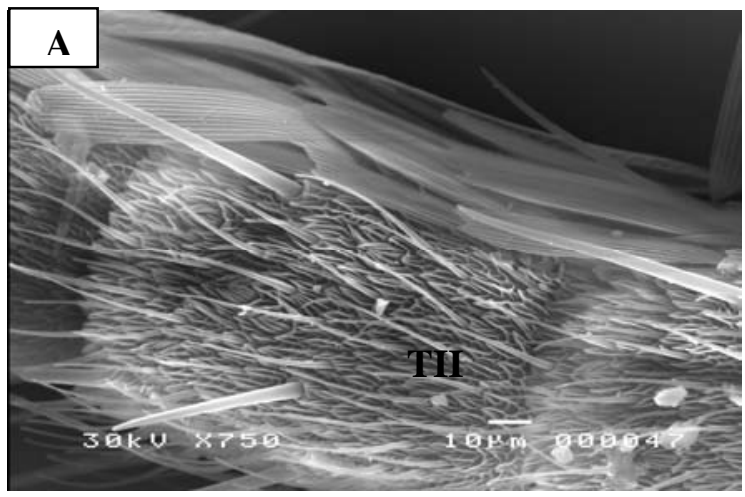

(A): Type II (TII) of trichoid sensilla, are short and present on both sexes.

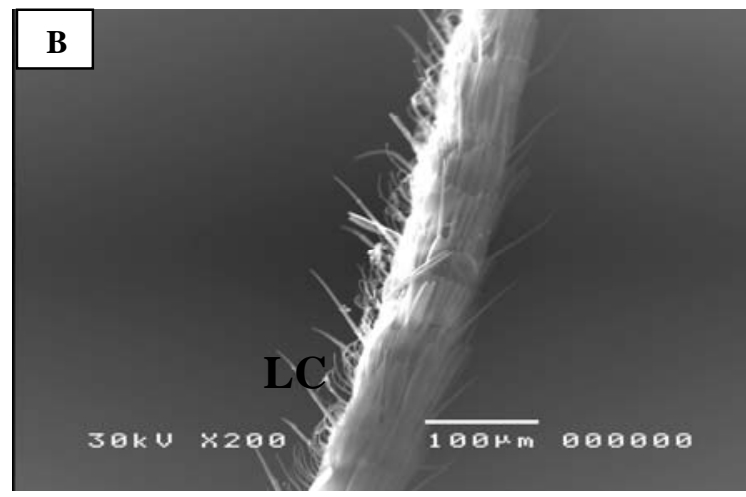

(B): General view of antennal sgment of male showing long chaetica sensilla found on the dorsal surface (LCs).

Fig. (2): Scanning electron microscopy of antennal sensilla of untreated $S$. littoralis 




(A): The apical segment of the antenna which has more than six chaetica sensilla.

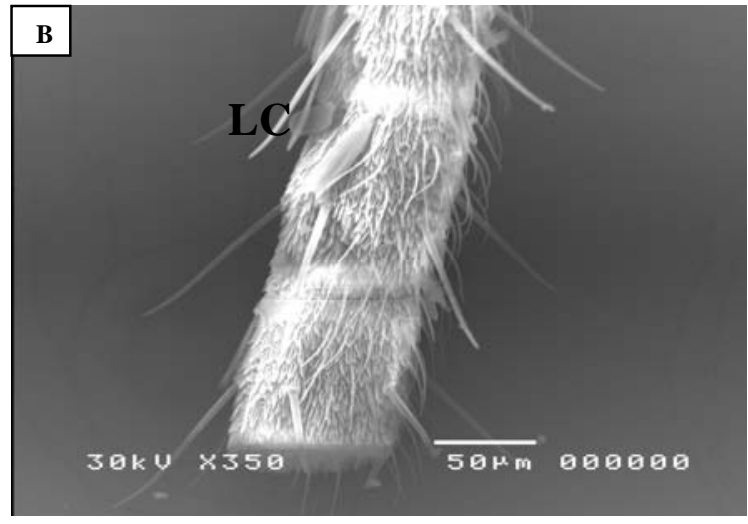

(B): Long chaetica sensilla (LC) on the lateroventral.

Fig. (3): Scanning electron microscopy of antennal sensilla of untreated S. littoralis :

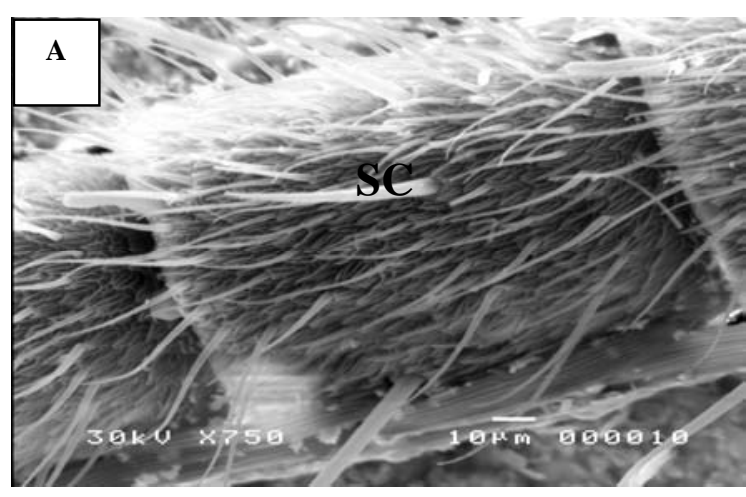

(A): Short chaetica sensilla (SC) localized on the medioventral space.

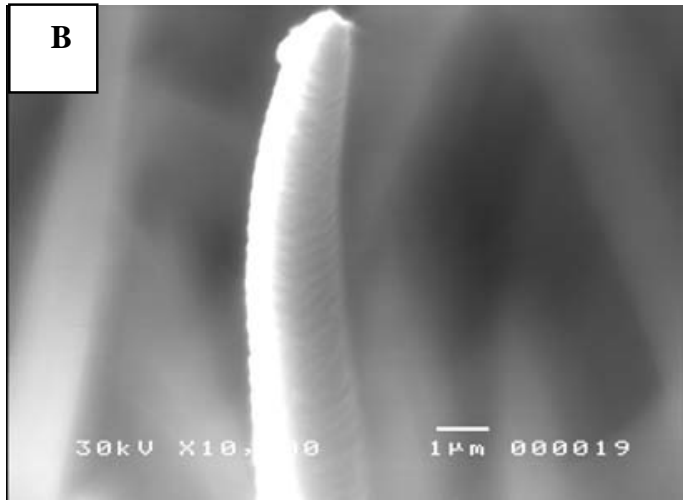

(B): Chaetica sensilla with circumferentially grooved.

Fig. (4): Scanning electron microscopy of antennal sensilla of untreated $S$. littoralis . 


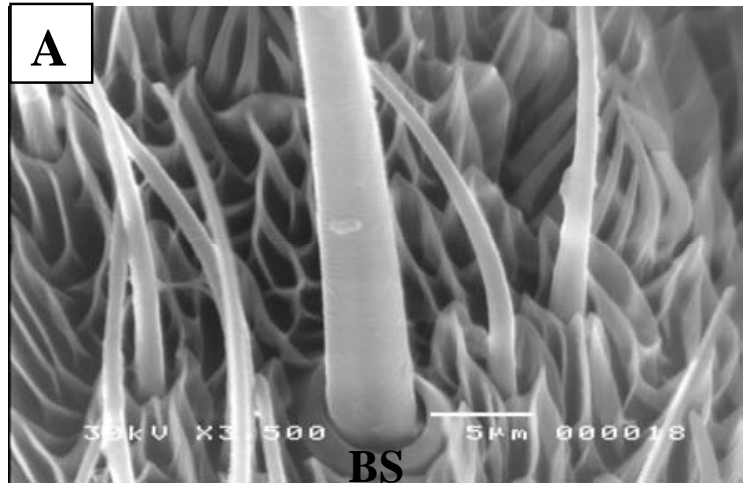

(A): The basal socket of chaetica sensilla (BS).

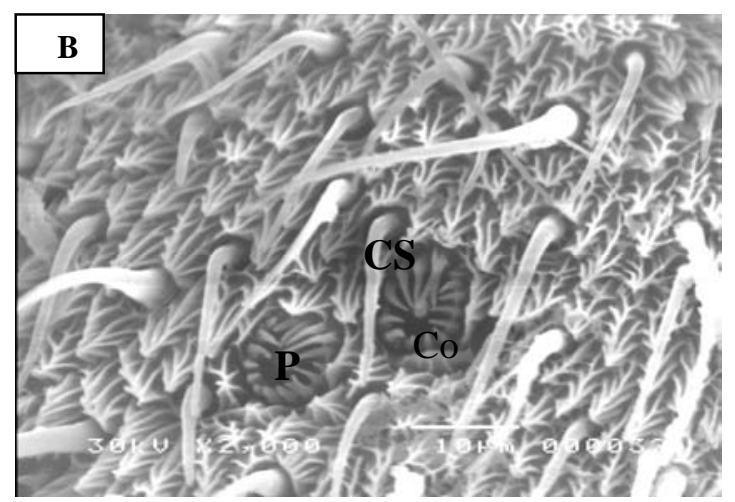

(B): Sensillum coeloconica $(\mathrm{Co})$, central peg is fluted (P) and the circular spines (CS).

Fig. (5): Scanning electron microscopy of antennal sensilla of untreated S. littoralis .

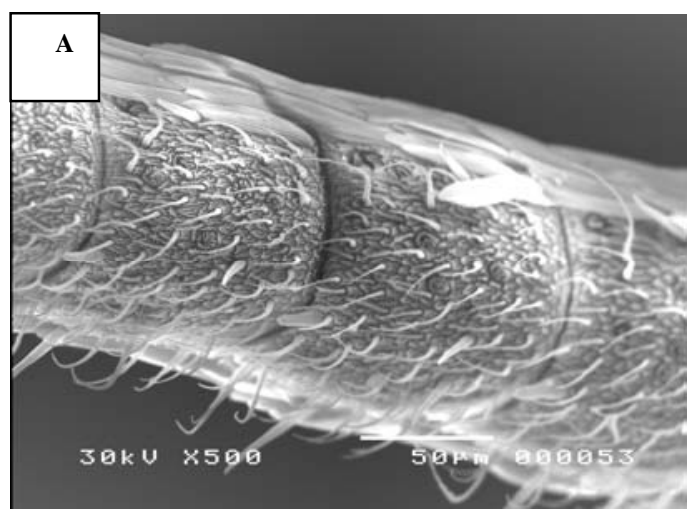

(A): Taste rod (TR) at the leading edge of each segment.

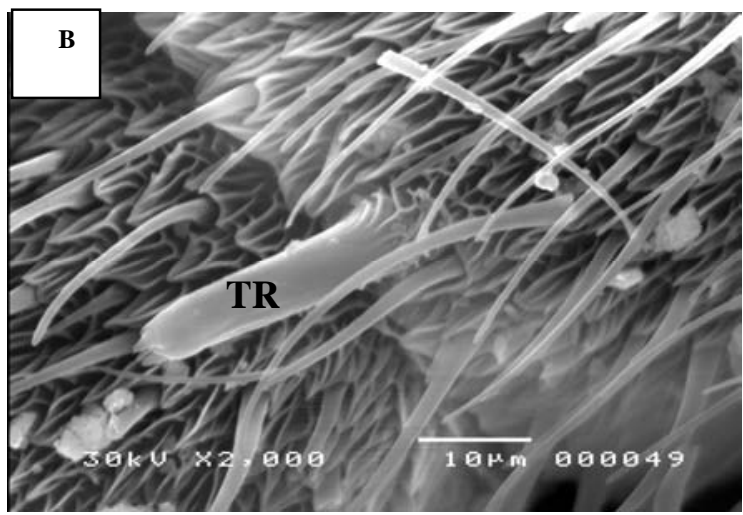

(B): Magnification of segment of the antenna showing taste rod (TR).

Fig. (6): Scanning electron microscopy of antennal sensilla of untreated S. littoralis . 


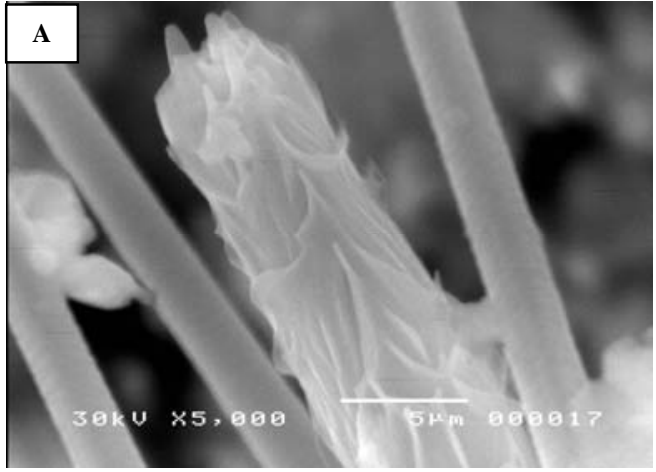

(A): The three cavity peg complexes at the tip (arrow).



(B): Two taste rods (TR) joined on the terminal segment.

Fig. (7): Scanning electron microscopy of antennal sensilla of untreated S. littoralis .

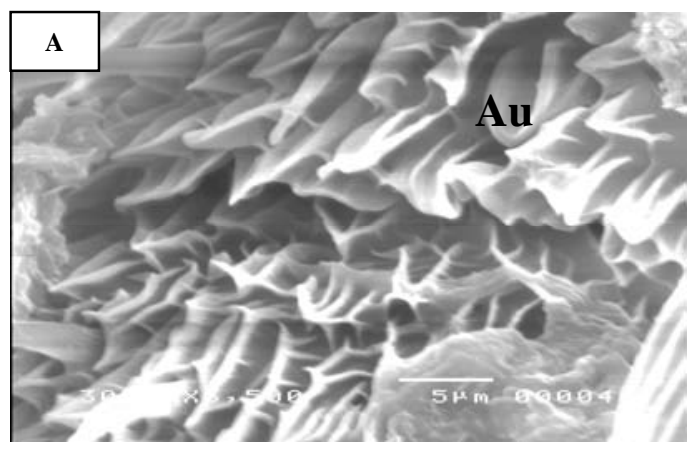

(A): Auricillica sensillum (Au).

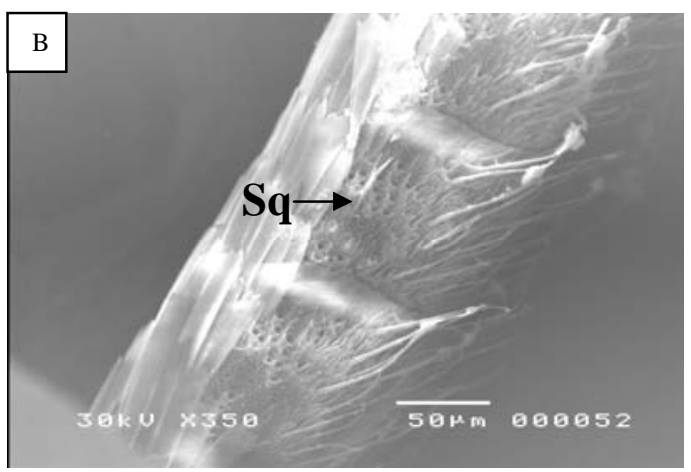

(B): Squamiform sensillum (Sq).

Fig. (8): Scanning electron microscopy of antennal sensilla of untreated S. littoralis . 


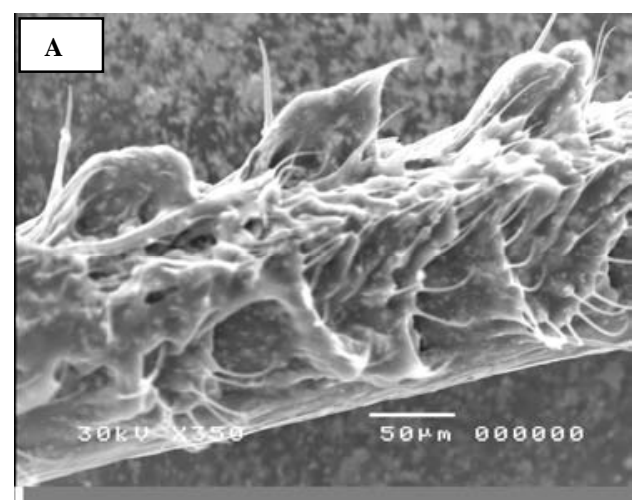

(A): Abnormal segments in the male antenna.

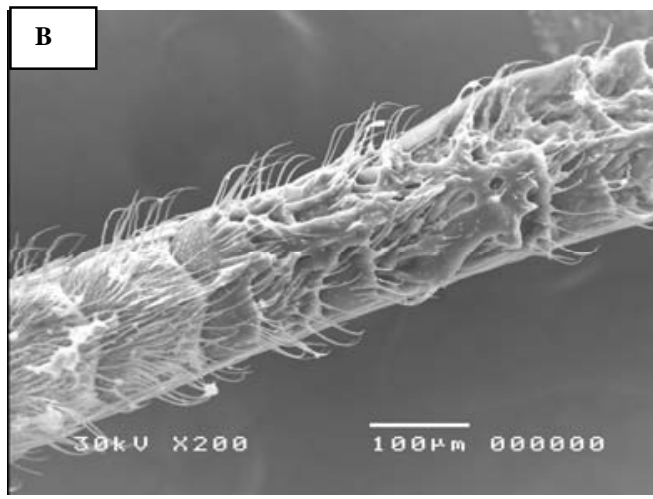

(B): General view of antennal segments of male showing abnormal distribution of sensilla.

Fig. (9): Scanning electron microscopy of antennal sensilla of treated S. littoralis .
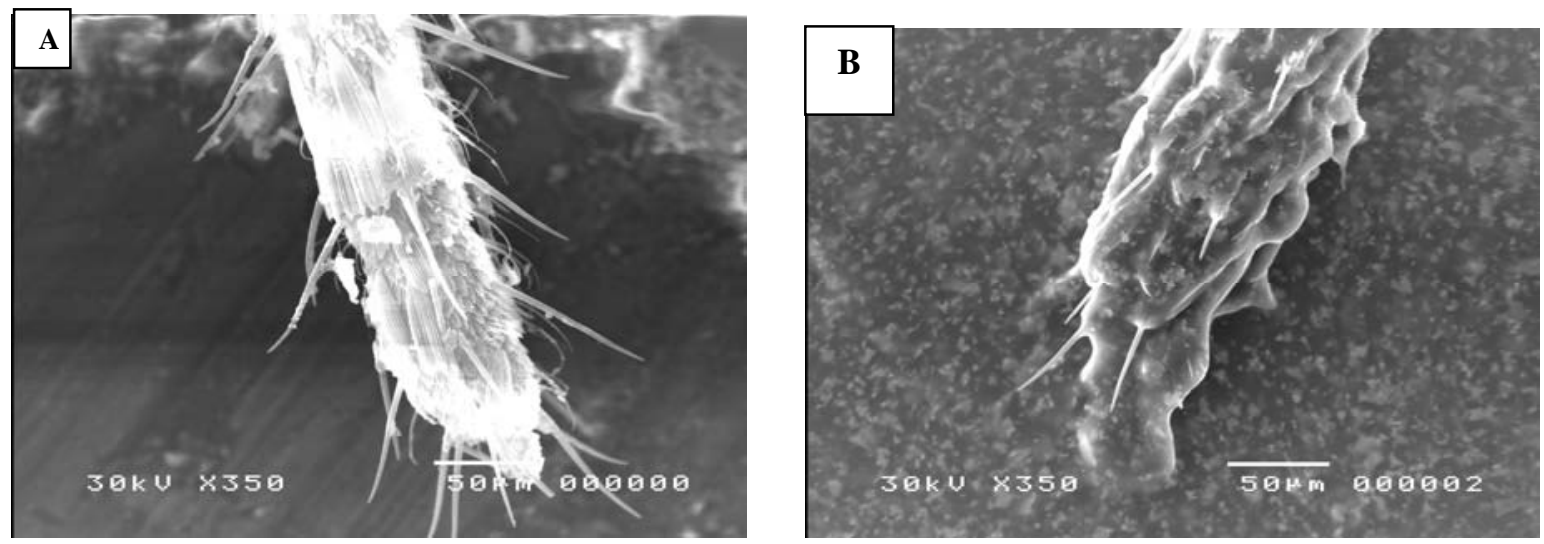

Fig. (10): Scanning electron microscopy of antennal sensilla of treated $S$. littoralis showing the apical part of the left and right antenna of treated male of the same specimen $(A \& B)$.

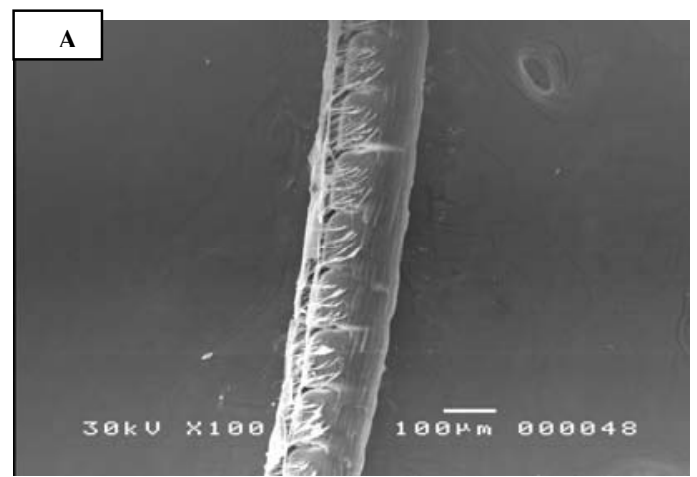

(A): Abnormal segments in the male antenna.

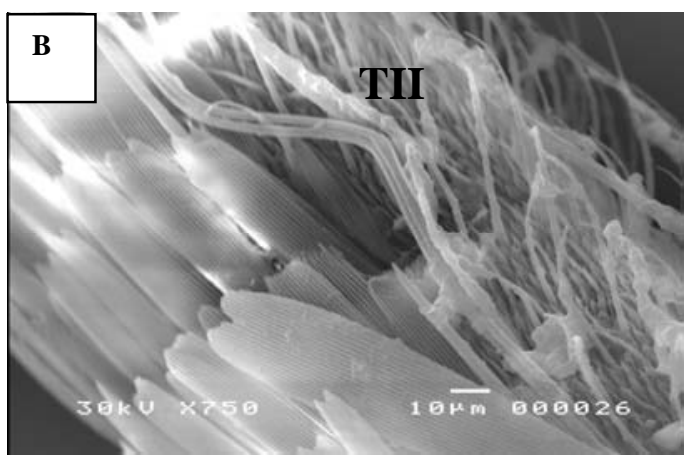

(B): Abnormal trichoid sensilla of type II (TII) in female.

Fig. (11): Scanning electron microscopy of antennal sensilla of treated S. littoralis . 


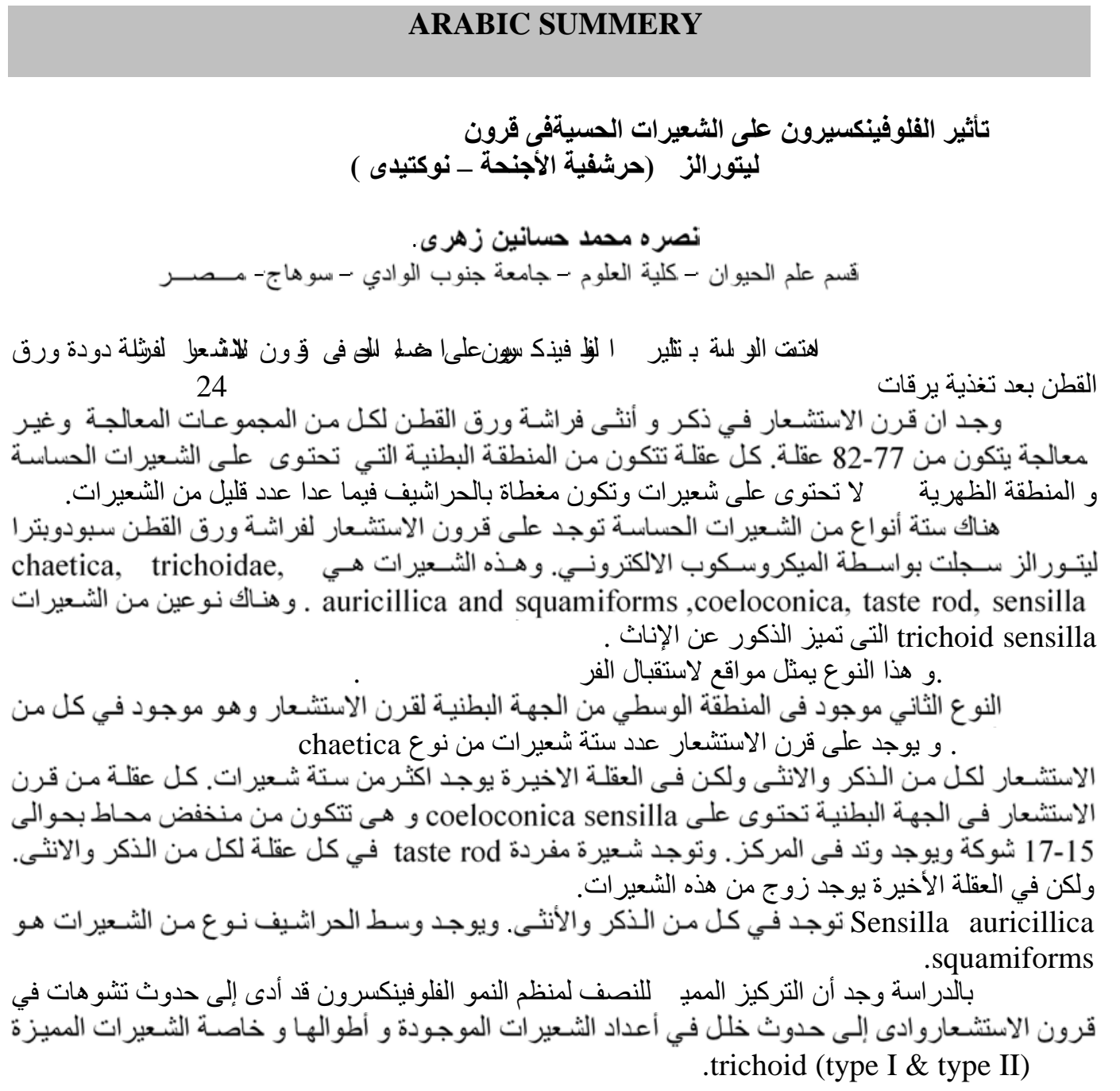

